\title{
MIGRACIÓN, RACISMO Y EXCLUSIÓN: ANÁLISIS DE LAS EXPERIENCIAS DE MUJERES LATINOAMERICANAS EN BARCELONA
}

\author{
Migration, Racism and Exclusion: Analysis of the Experiences of Latin \\ American Women in Barcelona \\ Paola Contreras Hernández \\ Universidad Autónoma de Barcelona \\ paolacontrerashz@gmail.com
}

\begin{abstract}
Resumen:
Este artículo tiene por objetivo explorar, por un lado, las prácticas racistas y dinámicas de exclusión social a las que se enfrentan mujeres latinoamericanas que residen en la ciudad de Barcelona $y$, por otro, analizar cómo ello repercute en su devenir migratorio. El sustento teórico se estructuró en torno al racismo, securitización de las fronteras y feminización de las migraciones. La metodología se definió desde un enfoque cualitativo mediante entrevistas semiestructuradas. El análisis se realizó desde el paradigma de la interseccionalidad y se sistematizó a partir de tres dimensiones: Migración, Racismo y Exclusión, las que permitieron evidenciar la articulación de un sistema que, al imitar el ejercicio de derechos, obstaculiza el devenir del colectivo de estudio.
\end{abstract}

\section{Palabras clave:}

Migración, feminización, racismo, exclusión.

\begin{abstract}
:
This article explores, on the one hand, the racist and dynamic practices of social exclusion faced by Latin American women residing in the city of Barcelona and, on the other hand, how this affects their migration. The theoretical framework was structured around racism, securitization of borders and feminization of migrations. The methodology was defined from a qualitative approach through semi-structured interviews. The analysis was made from the paradigm of intersectionality and it was systematized from three dimensions: Migration, Racism and Exclusion, which allowed to demonstrate the articulation of a system that, by imitating the exercise of rights, hinders the future of the collective of study.
\end{abstract}

\section{Keywords:}

Migration, Feminization, Racism, Exclusion.

Recibido: 29/04/2019 


\section{INTRODUCCIÓN}

Los procesos migratorios transnacionales son respuesta a los efectos que está causando el capitalismo: precarización de la vida, inestabilidad sociopolítica, deterioro medio ambiental, laboral y económico. La urgencia por buscar estabilidad y seguridad sitúa a Europa, en el mapa global, como un polo de atracción al perfilarse como paradigma de "calidad de vida". No obstante, su gestión migratoria ha tomado un cariz cada vez más restrictivo debido a la lógica de la seguridad nacional. Ciertamente, la securitización de las fronteras y las reiteradas reformas a las leyes migratorias son medidas que buscan limitar, frenar u obstaculizar la llegada y permanencia de población de "terceros países". A nivel interno, se observa un aumento en las deportaciones y controles policiales por perfil étnico (De la Serna, 2014; Jarrín, 2015), instancias que evidencian cómo la imbricación entre migración y racismo confluye bajo prácticas institucionales. Las violencias que emanan de esta intersección se encuentran situadas y encarnadas en cuerpos diferenciados por factores $y / o$ dimensiones que configuran escenarios complejos y diversos. En efecto, estas diferencias muestran a un "otro" que se debate entre una homogenización asignada por discursos totalizantes y una heterogeneidad constituida por experiencias que transgreden imaginarios estáticos.

En este contexto, el presente artículo tiene por objetivo explorar, por un lado, las prácticas racistas y dinámicas de exclusión social a las que se enfrentan mujeres latinoamericanas que residen en la ciudad de Barcelona y, por otro, cómo ello repercute en su devenir migratorio. Para situarlo, se presenta un marco teórico enfocado en el racismo, en tanto dimensión que rige y determina muchas de las prácticas sociales, subjetivas, políticas y económicas hacia los y las migrantes; en la securitización de las fronteras que la Unión Europea (UE) ha venido desarrollando; y en torno a la feminización de las migraciones. Posteriormente se detallan los aspectos metodológicos de la investigación; para luego pasar al análisis de los resultados. A partir de la triangulación entre migración, racismo y exclusión, se logra visualizar de qué manera la diferenciación social, cultural y normativa profundiza dinámicas de segregación y violencia. Por último, se presentan las conclusiones generales que arrojó el estudio.

\section{RACISMO COMO SISTEMA POLÍTICO, SOCIAL E INSTITUCIONAL}

El racismo se ha definido como un sistema de dominación y jerarquización global que otorga un valor diferenciado de lo humano. El sustento ideológico proviene de la imposición de la raza ${ }^{2}$ como ficción (Mbembe, 2016), el cual define al otro/a como un

\footnotetext{
${ }^{1}$ El Parlamento y Consejo europeo en la Directiva 2008/115/CE, en al art. 3.1 define a una nacional de un tercer país a cualquier persona que no sea ciudadano de la UE.

${ }^{2}$ El concepto de raza es en sí mismo un concepto que ha generado grandes y acalorados debates académicos y sociales, pero "si bien estos debates pueden resultar de mucho interés, lo que tenemos que destacar aquí es que nos encontramos ante una re-lectura del concepto de "raza", pues en las vertientes analíticas de la interseccionalidad se estima éste como una construcción social, además de desactivar su fuerte carga biologicista, pues, para que funcione
} 
objeto-excedente (Dussel, 2000; Fanon, 2010) que se articula a partir de marcadores y/o identificadores tales como la religión, el color de piel, el país de procedencia (en caso de ser migrantes), la lengua, la cultura, etc. (Grosfoguel, 2012). Precisamente, esta distinción constituye la base de los procesos de racialización que "tienen el propósito de identificar estos grupos de población y de fijar, con la mayor precisión posible, los límites dentro de los cuales pueden circular" (Mbembe, 2016: 80). Proceso que se inscribe dentro de un sistema global de control y explotación que refuerza la dominación racial mediante la imposición de ficciones identitarias ("negro", "blanco", "indio", "mestizo) y la imbricación de jerarquías de género, clase, religión, refuerza la dominación racial (Lugones, 2008, Quijano, 2000).

En el caso de la población migrada, la imagen antagónica que representa su no pertenencia en el país de destino nos advierte de cómo lo "ajeno" cuestiona el orden social, pues incorpora la "diferencia" como marcas que devienen en estigmas. Las prácticas discursivas, políticas, sociales y simbólicas en torno a ello, dificultan los procesos de integración que legitiman, directa o indirectamente, la segregación y construcción de la otredad.

Ahora bien, el racismo hacia la población migrada se manifiesta de forma multidimensional; a nivel social se expresa en las representaciones negativas que acentúan "la problemática relación que existiría con la población extranjera, agudizando actitudes xenófobas bajo la simbiosis "diferente-igual-peligroso" (Contreras, 2016: 65). A nivel político-institucional lo hace a través de políticas migratorias que establecen límites de entrada y permanencia, pues se busca prevalecer, por un lado, las identidades nacionales, y por otro, la seguridad interna (Agrela, 2002). Precisamente, el racismo institucional se entiende como violencia de Estado, pues sitúa a la población migrante en un nivel inferior de acceso y reconocimiento de derechos que los excluye de la ciudadanía plena (Solana, 2001). Un ejemplo de ello se observa con la exclusión sanitaria que se ejecutó en España durante el año 2012 (Real Decreto-ley 16/2012).

Este tipo de disposiciones nos permite analizar de qué manera la construcción política de la ciudadanía acentúa la diferenciación entre las personas migrantes y autóctonas, y cómo ello intensifica los procesos de exclusión social, carencia de bienestar, privación de vínculos sociales e integración política; provocando una ruptura progresiva entre el individuo y la sociedad (Silver, 1994).

\section{SECURITIZACIÓN DE LAS FRONTERAS Y DISPOSITIVOS DE CONTROL}

Durante las últimas décadas Europa ha visto incrementada la presencia de población procedente de países catalogados como subdesarrollados; situación que ha generado hostilidad social que se expresa bajo la necesidad de proteger sus economías, identidades culturales y seguridad interna, siendo argumentos suficientes para "justificar, legitimar y promover restricciones en las políticas migratorias, reforzar los controles fronterizos, así como otorgar un tratamiento diferenciado (discriminatorio) a

analíticamente sólo se comprende la "raza" en términos de intersección con la diferencias de etnia, género y clase" (Guzmán, 2011: 874). 
los migrantes residentes en los países europeos" (Sánchez, 2013: 138). La urgencia por excluir esta "peligrosidad" del hábitat social o evitar que lo habite, se ha constituido como eje para fortalecer las fronteras y agudizar los mecanismos de control, disuasión y represión frente a esta "invasión silenciosa" (Contreras, 2016).

En concordancia con ello, el aumento de controles fronterizos plantea la existencia de una frontera biopolítica generalizada (Vaughan- Williams, 2009) que sirve para establecer límites políticos, de raza y clase que, a nivel material y simbólico, definen líneas divisorias en los Estados-nación. El despliegue de mecanismos de control y disuasión muestran la fronterización de la UE que, sustentada por una nueva racionalidad punitiva, se resguarda y defiende de la otredad racializada.

Este síndrome securitario ha derivado en la implementación de dispositivos de control entre los que destaca la Agencia Frontex, la cual tiene como objetivo gestionar las fronteras exteriores para combatir la inmigración ilegal, la trata de personas y prevenir las amenazas para la seguridad interna, la salud pública y las relaciones internacionales de los Estados miembros. Como complemento, en el año 2016 entra en vigor la Guardia Europea de Fronteras y Costas para frenar la llegada de inmigrantes y refugiados durante 2015 y 2016. Por otra parte, la UE definió la Agenda Europea de Migración que busca afrontar los retos que implica la migración, proponiendo cuatro puntos de acción: reducir los incentivos a la migración irregular y forzada de ciudadanos/as de terceros países; reforzar las medidas desarrolladas por Frontex para una eficaz gestión de las fronteras; instaurar un nuevo modelo de seguimiento y evaluación del Sistema Europeo Común de Asilo; y definir una nueva política de migración legal con fines laborales.

Ahora bien, los Estados miembros de la UE han fortalecido las estrategias políticojurídicas que obstaculizan la estancia y permanencia de la población migrada. En el caso español, la gestión migratoria se organiza a través de la Ley Orgánica 4/2000 que, tras sucesivas reformas, presenta una tendencia a controlar la migración irregular y establecer una diferencia normativa entre la población migrada dependiendo del estatus jurídico que adquieren (regular/irregular; estudiante/trabajador; residencia permanente/transitoria, etc.). En la misma dirección, la Ley Orgánica 4/2015 sobre Protección de la Seguridad Ciudadana señala que

Los extranjeros/as que sean detectados en la línea fronteriza de la demarcación territorial de Ceuta o Melilla mientras intentan superar los elementos de contención fronterizos para cruzar irregularmente la frontera podrán ser rechazados a fin de impedir su entrada ilegal a España (Disposición adicional 10 $10^{\mathrm{a}}$, punto 1 ).

Otro dispositivo de control es el Real Decreto 162/2014 que establece el reglamento de funcionamiento de los Centros de Internamientos de Extranjeros ${ }^{3}$ (CIE), señalan que su finalidad es la custodia preventiva y cautelar de los extranjeros/as que

\footnotetext{
${ }^{3}$ Los Centro de Internamientos de Extranjeros (CIE) aparecen en el ordenamiento jurídico español con la Ley Orgánica 7/1985 (primera ley de extranjería), como medida cautelar -no penitenciaria- vinculada a un expediente de expulsión. Pues bien, en 2014 se aprueba el reglamento.
} 
estén bajo situación de expulsión o devolución. Por último, se encuentra la Brigada de Delincuentes Extranjeros (BEDEX) encargada de las expulsiones cualificadas (Fernández, 2010).

Estas medidas nos permiten situar la relación entre Colonialidad y Migración, en tanto que actúan sobre un "otro-abyecto" que, leído en clave decolonial, acontece como producto de relaciones de poder, violencia y dominación, primero en un mundo colonial y posteriormente en la Colonialidad global, manifestándose a través de dinámicas sociales, políticas e institucionales que inferiorizan a la población migrada.

\section{PROCESOS MIGRATORIOS FEMENINOS}

El protagonismo de las mujeres en los procesos migratorios ha transformado el patrón de movilidad: éstas han dejado de ser parte de un proceso asociativo masculino para pasar a uno de carácter autónomo como estrategia familiar y personal (Tapia, 2011). Con todo y dicho brevemente, la feminización ${ }^{4}$ de las migraciones se circunscribe en un escenario global de transformaciones sistémicas.

Ahora bien, la incorporación de la categoría de género en las investigaciones sobre migración certifica un cambio epistemológico que, posteriormente, es profundizado con la incorporación del paradigma de la interseccionalidad. Esta perspectiva analiza cómo, mediante la intersección de las categorías de género, raza, clase, opción sexual, edad, religión, país de procedencia, etc., se definen un mapa situacional donde convergen distintos niveles de jerarquización y desigualdad. Este análisis facilita y otorga una mayor aproximación al impacto político y social que tiene la subordinación más allá de una lectura centrada en las implicancias del género (Nash, 2008; Phoenix, Pattynama, 2006). En efecto, la interseccionalidad plantea que los diversos modelos de opresión (sexismo, racismo, clasismo) no actúan de manera separada, sino que se imbrican y forjan una estructura de dominación articulada (Davis, 2004).

Por ello que, al estudiar los procesos migratorios femeninos, la interseccionalidad permite explorar la forma en que se estructuran y complejizan las violencias, opresiones, desigualdades y discriminaciones que se observa a nivel "legal (visado, proceso de regulación, ley de extranjería, etc.), económica (nichos laborales, explotación, subempleo, etc.), política (asimilacionista, segregacionista, etc.),

${ }^{4}$ La feminización, tal y como señala Gutiérrez (2010) responde a la explotación y codificación de la fuerza de trabajo marcada por la precariedad, cuyo fundamento gira sobre la subalternización arraigada en la colonialidad del trabajo. Un ejemplo de ello es el trabajo del hogar y del cuidado "en tanto que trabajo afectivo, es una expresión de las desigualdades globales impresas en los cuerpos de las mujeres (...). Desde este punto de vista, la herencia del orden colonial —reactivada mediante la segregación racial y de género del mercado de trabajo y de las políticas migratorias deshumanizadoras - se deja sentir a nivel individual y moviliza nuestros encuentros cotidianos, remitiéndonos a lo que Aníbal Quijano analiza como la "colonialidad del trabajo". 
antropológica (interculturalidad, conflicto de valores, etc.), psicológica (estrés adaptativo, procesos psicopatológicos, habilidades sociales, relacionales intergrupales, etc.), entre otras" (Martínez García; García Ramírez; Maya Jariego, 1999: 222). A eso se suma el rol que juegan las leyes migratorias de cada estado que, de manera general, promueven "una visión utilitarista, negativa y amenazante de lo que supone ser inmigrante y de las consecuencias problemáticas de su presencia" (Agrela, 2002: 94).

La multicausalidad y multidimensionalidad de la feminización de las migraciones viene a corroborar la confluencia de factores y dinámicas opresivas que enfrentan las mujeres en dicho proceso. En el caso español a partir de la década de los noventa y producto del crecimiento económico, las mujeres autóctonas dejaron de realizar labores de cuidado y reproducción debido a su incorporación al mercado laboral, responsabilidad que recayó en mujeres inmigrantes no-comunitarias, en especial latinoamericanas. Esto generó una internacionalización, externalización y mercantilización de estas tareas definidas principalmente por divisiones de género, clase, raza (Oso y Parella, 2014).

\section{ASPECTOS METODOLÓGICOS Y EJES CONCEPTUALES DE ANÁLISIS}

Este artículo presenta una parte de los resultados de la tesis doctoral que entre sus objetivos buscaba explorar, por un lado, las prácticas racistas y dinámicas de exclusión social a las que se enfrentan mujeres latinoamericanas que residen en la ciudad de Barcelona y, por otro, cómo ello repercute en su devenir migratorio. El trabajo metodológico se definió desde un enfoque cualitativo, en tanto que permite recoger y analizar discursos, contenidos y contextos, posibilitando la exploración e identificación de los problemas de la realidad investigada. La muestra se definió a partir de un muestreo intencional y la selección se logró mediante el diseño de un casillero tipológico orientado a considerar una mayor heterogeneidad y variabilidad a los discursos. Se realizaron 25 entrevistas semiestructuradas a mujeres de distintas procedencias de América del Sur, Centro y Caribe: Chile, Argentina, Uruguay, Perú, Bolivia, Ecuador, México; Colombia; Paraguay; República Dominicana; Costa Rica ${ }^{5}$. A través del programa Atlas-ti se logró sistematizar y codificar la información utilizando tres conceptos claves: Migración, Racismo y Exclusión. El análisis, organizado desde el paradigma de la interseccionalidad, nos permitió conectar categorías/factores que interactúan y generan múltiples y simultáneos niveles de discriminación y violencia, visualizando con ello la manera en que las desigualdades de género se articulan con otras jerarquías sociales que instauran una matriz que establece modelos de opresión.

\footnotetext{
${ }^{5}$ En esta investigación se entiende por Latinoamérica como un ámbito geopolítico-relacional vinculado a experiencias históricas compartidas. Por ello se incluyen países de América del Sur, Centro, Norte y Caribe.
} 


\section{ANÁLISIS DESDE LAS EXPERIENCIAS SITUADAS}

En este apartado se presenta el análisis que conectó la similitud de experiencias en torno a la migración, racismo y exclusiones, además de situar aspectos que tienden a confluir y generar una serie de situaciones que incrementan la fragilidad social.

El periodo pre-migratorio es un momento de incertidumbres y desafíos, de cambios y transformaciones para quien decide emigrar. Para varias de las mujeres entrevistadas una de las cuestiones que más resuena de este periodo era el miedo a ser "devueltas", es decir, no ser admitidas en España por no cumplir con los requisitos que exige el Ministerio de Asuntos Exteriores. Cerca de un 70\% de las participantes entró al país como turistas, debiendo cumplir una serie de obligaciones establecidas en el Reglamento (EU) 2016/399 del Parlamento Europeo y del Consejo ${ }^{6}$. Dentro de estas obligaciones destaca la carta de invitación o justificativo de hospedaje, billete de vuelta y acreditar medios económicos para la estancia (73€ diarios). Existen algunos países de América que además de estas exigencias deben obtener un visado en la embajada de España en el país de origen; este es el caso de Bolivia, Cuba, Ecuador, Haití, República Dominicana. Así lo ejemplifica el siguiente relato ${ }^{7}$ :

Para mí fue difícil llegar, porque primero tuve que sacar la visa, pero en la Embajada no son muy simpáticos y en todo momento te miran con desconfianza y no te dan toda la información. Luego al llegar a Madrid y pasar por policía temblaba, porque saben que nosotras venimos para quedarnos y a mejorar nuestras vidas (Estefanía, 52 años, procedente de Ecuador, 13 años de residencia en Barcelona).

El relato deja entrever la forma en que el país receptor extiende sus fronteras hasta el país de origen de la persona que emigra, pues las exigencias que deben cumplir son el primer filtro de entrada. En este sentido, los requisitos que los estados miembros de la UE imponen a los ciudadanos/as de terceros países son cada vez más exigentes y menos flexibles, a lo que se añade una diferencia normativa con los ciudadanos/as comunitarios que provoca desigualdad jurídica, política y social que limita el acceso a posibilidades laborales o de desarrollo social. En efecto, las políticas migratorias se construyen como estructuras de significados que, por un lado, sustenta un sistema que discrimina y por otro, ejerce racismo institucional que solidifica la distinción binaria entre desarrollado/subdesarrollado, derechos/deberes que influye en la representación prototípica de la otredad (migración no-comunitaria) desde fundamentos ideológicos y normativos.

Ahora bien, una vez sorteada esta primera barrera y asentadas en el país de destino las dificultades no desaparecen. Para quienes ingresan como turistas, es necesario gestionar el permiso de residencia; requisito indispensable para acceder a servicios

\footnotetext{
${ }^{6}$ Véase

http://www.exteriores.gob.es/Portal/es/ServiciosAlCiudadano/InformacionParaExtranjeros/Pagi nas/RequisitosDeEntrada.aspx

7 Para respetar de la confidencialidad de las participantes los nombres utilizados son seudónimos.
} 
básicos (salud, educación, prestaciones sociales, etc.). Pero la obtención de este permiso resulta engorroso debido a los constantes cambios en el reglamento de extranjería. Algunas de las participantes estuvieron en situación administrativa irregular por un largo tiempo, lo que provocó una pérdida de derechos, dificultad de alquilar una vivienda, limitación de acceso sanitario, imposibilidad de obtener trabajo formal, entre otras limitaciones.

\begin{abstract}
Yo estuve 3 años sin papeles. Trabajé en una casa12 horas diarias y me pagaban $15 €$ el día, la casa era enorme y yo no aguanté y le dije a la señora que no por ser negra me iba a tratar como esclava, a lo que ella me dijo "sino te gusta pues fuera, hay muchas que tomarán el trabajo. Hasta que no tuve papeles esa fue la tónica de trabajo (Marina, 56 años, procedente de Perú, 8 años de residencia en Barcelona).
\end{abstract}

La condición jurídica de las extranjeras "incide directamente en su vida cotidiana e influyen de manera determinante en su acceso a derechos y oportunidades" (Oso y Parella, 2012: 14). De hecho, esta experiencia muestra, por un lado, la vulneración de derechos a la cual están expuesta las personas que residen de manera irregular, y por otro, la reflexividad de la participante al asociar negritud (raza) con esclavitud, situando un componente crítico que responde a la construcción identitaria que refleja de qué manera lo "negro" recae en personas que viven abusos, ilegalidad e injusticia. Desde una perspectiva más general, cabría señalar que, si bien la ciudad de Barcelona alberga una multiplicidad de nacionalidades, las discriminaciones que enfrentan las mujeres inmigrantes a raíz de la confluencia entre género, raza/etnia, nacionalidad y/o rasgos fenotípicos, forjan identidades "etnificadas" (Delgado, 2009) que actúan como sustento de prácticas sociales racistas.

Retomando la cita, la participante asocia lo negro con esclavitud, explotación laboral y vulneración de derechos; pero si analizamos el rol de la empleadora, observamos que aprovecha la situación de la mujer inmigrante (necesidad, precariedad y sin permiso de residencia) para suplir las labores domésticas en condiciones de precariedad, desigualdad salarial y sin reconocimiento de derechos laborales al no existir mecanismos que supervisen los abusos que se dan en este ámbito (Contreras, 2015).

Frente a esto, es importante mencionar que hasta el año 2015, el 32\% de las mujeres inmigrantes (extracomunitarias) en el país se dedicaba al servicio doméstico (OIM, 2015). Si bien, mediante el Real Decreto 1620/2011 se reguló este trabajo, en la práctica las condiciones laborales continúan siendo informales y sin prestación por desempleo o enfermedades. En disposición de ello, la Conferencia Internacional del Trabajo (OIT) adoptó el convenio 189 sobre las trabajadoras domésticas con el objetivo de establecer derechos básicos. No obstante, en el año 2013 el gobierno español propuso al parlamento la no ratificación del convenio, profundizando con ello la exclusión social a la cual están expuestas (Contreras; Gómez y Santa Cruz, 2017).

En otro aspecto, para las participantes la primera etapa en la ciudad fue compleja debido a dos cuestiones, por un lado, a la distancia, soledad y añoranza de la familia, amigos y contexto social del país de origen; y por otro, sentir la diferencia que implica ser migrante, es decir, comprender de qué manera la ausencia de vínculos identitarios 
(con España y Cataluña), el desconocimiento de las costumbres, el idioma y la diferencia fenotípica fueron determinando una distancia con la población autóctona.

Mis primeras impresiones cuando llegué fueron agridulces, estaba contenta de haber llegado a una ciudad tan linda, pero me sentía extraña, no encajaba en ninguna parte; además me veía tan diferente de las mujeres de acá, lo quiera o no, tengo cara de "india" (Lorena, 45 años, procedente de Ecuador, dos años de residencia en Barcelona).

El desarraigo social es un factor que complejiza el devenir migratorio, pues supone una descontextualización del hábitat al debilitar la interacción simbólica-identitaria que las relaciona con la memoria colectiva del país de origen. A esto se suma que, al verse y sentirse diferente, aumenta la inseguridad personal. El sentimiento de inferioridad en torno a "ser india" proyecta aspectos subjetivos de una memoria histórica de violencia y colonización, que, frente al ideario europeo-blanco, configuró identidades subalternas. En efecto, los prejuicios y representaciones sociales actúan como dispositivos de exclusión hacia la figura de la mujer migrante (en especial haca las latinoamericanas) al proyectar un imaginario que las sitúa como portadoras y reproductoras de valores patriarcales, pasivas y dependientes de sus parejas, cariñosas y cuidadoras, que utilizan la "estética de la seducción" como herramienta para lograr sus objetivos. Perfil negativo que interfiere a la hora de establecer vínculos con la población local. Por consiguiente, la responsabilidad que los Estados y la sociedad civil tienen a la hora de gestionar la integración es fundamental; no obstante, una de las críticas a los procesos de integración es que se confunde con asimilación de las características culturales de la sociedad de destino.

Las discriminaciones y exclusiones que viven las mujeres migradas no-comunitarias se observa en las restricciones en el ejercicio de derechos fundamentales, acentuadas a raíz de la crisis económica que vivió España a partir del año 2008 y que puso al descubierto la fragilidad a la cual estaban expuestas (Cruz Roja, 2014).

El racismo como otras formas de exclusión social son una realidad que las personas migradas enfrentan; discursos y actitudes que establecen una distinción negativa y que como consecuencia provocan marginación, aislamiento, desarraigo y desigualdad social. El desprecio por aquello que considerado inferior funda efectos adversos en las personas que lo viven: miedo al rechazo e inseguridad que van permeando la subjetividad.

Considerando las experiencias de las participantes, observamos algunos ejemplos de cómo en el área social y administrativo-jurídico se (re)producen prácticas racistas:

Cuando busco trabajo lo que más me irrita son los anuncios que dice "solo para españoles", o sea, se nos rechaza de antemano por no ser de aquí. Además, con la crisis la cosa esta muy mal para nosotras y ellos lo saben (América, 34 años, procedente de Bolivia, 9 años de residencia en Barcelona).

No entiendo por qué cuando vas a alquilar un piso te lo niegan sólo por ser migrantes, ellos te dicen "estamos buscando otro perfil (Karina, 49 años, procedente de Perú, 14 años de residencia). 
Si no tienes papeles no tienes derecho a nada, además en extranjería las cosas cambian cada mes y si no tienes un abogado que te asesores puedes pasar años así (Yohana, 49 años, procedente de Ecuador, 10 años de residencia en Barcelona).

El primer relato evidencia cómo la exclusión por nacionalidad es un elemento de segregación laboral. Asimismo, y a partir de la recesión económica (2008-2015) la población migrada se vio fuertemente afectada: desempleo de larga duración, carencia de contrato, empeoramiento de las condiciones laborales, mayor desprotección frente a abusos y arbitrariedades, salarios inferiores que la población autóctona, jornadas extensas, no disposición de los días reglamentarios de descanso, impago de horas extras, despidos injustificados (Martínez y Téllez, 2017; Vázquez; Vargas y Aller, 2014). En el caso femenino, la segmentación racial y de género determina el acceso laboral, pues, más allá de la cualificación profesional, acceden a nichos preestablecidos: servicio doméstico, de cuidados y hostelería (Solana, 2001).

El segundo relato destaca el problema de la vivienda. La mayoría de la población migrada establece su residencia bajo el régimen de alquiler, pero los bajos salarios, el desempleo y las prácticas discriminatorias de los propietarios complejizan el acceso a una vivienda digna (Onrubia, 2010). Resulta ilustrativo el testing realizado por SOS Racimo en el año 2015, donde se pudo medir la discriminación que sufren las personas migrantes a la hora de acceder a una vivienda. Una de las evidencias que arrojó el estudio, fue que, de las 462 llamadas telefónicas a agencias inmobiliarias, el $69,8 \%$ denegó la existencia de pisos en alquiler a personas de origen extranjero. Además, otro elemento a destacar es que las zonas que presentan degradación urbana por falta de inversión pública "es reemplazada por grupos sociales con menor nivel de renta, obligados por su situación socioeconómica a reutilizar unas viviendas degradadas, y, por consiguiente, de menor coste de acceso" (Onrubia, 2010: 11). La problemática de la vivienda es un tema complejo, en tanto que las limitaciones de acceso y el deterioro de algunos barrios favorece la conformación de guetos habitacionales que van acompañados de problemas colaterales como el hacinamiento o deserción escolar, haciendo del estigma y la exclusión una tendencia en alza que perjudica a los colectivos y/o grupos sociales que lo habitan. Así lo relata una mujer que vive en el barrio situado en la ciudad de Barcelona y catalogado de "marginal":

Aquí vivimos los que nadie quiere, los gitanos, los moros, los sudacas, los africanos que viven del top manta [venta callejera]. Si vives acá ya estás estigmatizada, pero esto fue lo único que encontré para vivir, imagínate sin trabajo, sin papeles, ¿quién me iba alquilar? (Delia, 29 años, procedente de Paraguay, 4 años de residencia en Barcelona).

Nuevamente la intersección de factores profundiza la desigualdad y segregación; ser inmigrante -independiente de tu formación profesional-, con una situación administrativa irregular, sobreviviendo en la economía sumergida, con escasas posibilidades de acceder a una vivienda digna, aumenta los niveles de exclusión social.

El tercer relato muestra los problemas que tienen aquellas que residen de la manera irregular. Esta "condición" imposibilita cualquier iniciativa o posibilidad económica, 
educativa e incluso restringe -como ya se ha señalado- derechos fundamentales, como, por ejemplo, el derecho a la atención sanitaria. La irregularidad administrativa limita las perspectivas de inclusión en la estructura social, consolidando con ello fronteras simbólicas. En efecto, los derechos civiles, culturales, económicos, sociales y políticos se encuentran condicionados por la condición administrativa de la persona migrada (Ghosh 2008). Por ello, el debate entre migración y derechos humanos "necesita de un dialogo social amplio con todos los actores involucrados: migrantes, actores políticos y sociales del país de origen, tránsito y destino en donde cada uno de éstos se reconozca como interlocutores legítimos y que esté centrado en el reconocimiento de los derechos como eje fundamental de las acciones a impulsar" (Contreras, 2016: 82).

\section{CONSIDERACIONES FINALES}

Desde una reflexión situada, las experiencias analizadas nos ofrecen la posibilidad de aproximarnos a las distintas expresiones del racismo y la exclusión; situaciones que han permitido observar cómo se entrelazan factores y/o dimensiones que, más allá del género, van conformando una estructura de dominación y violencia. Es decir, no solo por el hecho de ser mujeres es que se ejercen estas prácticas, sino por la conjugación factores tales como la condición de migrantes, el país de procedencia, el color de piel, los rasgos fenotípicos, etc. Por ello creemos que la interseccionalidad, como perspectiva de análisis, nos permitió entender las discriminaciones y las consecuencias que tiene en la vida de quienes lo viven. Es imbricación de textos, contextos y significados de estas experiencias sitúan a la migración como un campo reflexivo donde las violencias (simbólicas y materiales) son leídas como acciones racistas que acentúan la segregación. Observamos que el andamiaje que estructura los procesos de exclusión y despliegue del racismo se expresan en espacios que van determinando distintos ritmos y espacialidades. Primero, el espacio económico, el cual gira en torno al abuso, explotación y precarización laboral. El segundo, el espacio político/institucional formulado mediante la irregularidad administrativa y limitación de derechos. $\mathrm{Y}$ el tercero, el espacio relacionado con estereotipos, prejuicios, homogenización, violencia y subalternidad. Áreas que se formulan y expresan de maneras diversas y no siempre mantiene la misma intensidad y continuidad; se dilatan y contraen, pero ello no significa que se amortigüe su finalidad y sentido procesual. Es más, son estas variaciones las que otorgan -desde una perspectiva multidimensionalcomplejidad al proceso. En este sentido, urge desarrollar análisis que conecten racismo, dispositivos de control y feminización de las migraciones y que adviertan de las consecuencias prácticas que ello tiene en la vida de las mujeres migrantes. Precisamente, no deja de llamar la atención que la inclusión social se encuentra subordinada a la situación administrativa y que, dependiendo de ello, será el grado de acceso y limitación a derechos y/o bienestar social.

Ahora bien, observamos que, por un lado, los estados miembros de la UE despliegan políticas migratorias que endurecen la entrada y permanencia de personas migrantes $y$, por otro, que existe demanda de mano de obra femenina, especialmente el servicio doméstico y de cuidados. Lo que esto demuestra es que son precisamente; pareciera ser que hay una contradicción. Pero en realidad 
(...) la entrada de mano de obra inmigrada femenina y el recorte de sus derechos en el país de destino abaratan enormemente los costes salariales, ciertos gastos sociales y, además, en el caso de las trabajadoras del sector "cuidados", permite cubrir las necesidades reproductivas de los países de destino con un bajo coste monetario. Es la forma en que el neoliberalismo, ante su crisis de cuidados, ha reorganizado el género a escala global (Balaguer, 2012: 150).

Son estas dinámicas las que permiten entender cómo, desde imaginarios simbólicos, discursivos y pragmáticos, se define una alteridad migrante que se expresan cotidianamente en el tejido social y crean una atmosfera que excluye o no reconoce al otro/a. De ahí que el tema migratorio, en toda su magnitud, sea un tema relevante a bordar desde lo epistemológico, político, económico y social, puesto que permite observar y analizar hasta qué punto se vulneran los derechos humanos hacia las personas que emigran; cómo se articulan y reproducen desigualdades y diferencias de clase, género y raza; qué tipo de subjetividad se entreteje en las mujeres en base a esta experiencia; cuáles son las distintas aristas que implica la feminización de las migraciones, etc. (Pedone, 2007; Sinke, 2006).

Por último, es importante mencionar que, si bien existe heterogeneidad en los colectivos migrantes y sus trayectorias, el análisis se centró en elementos que generaron saturación de los discursos, es decir, los más reiterativos entre las entrevistadas, buscando con ello, resaltar factores estructurales que acentúan procesos de exclusión y violencia racista de manera general.

\section{BIBLIOGRAFÍA}

AGRELA, Belén. (2002). "La política de Inmigración en España: reflexiones sobre la emergencia del discurso de la diferencia cultural". Migraciones Internacionales, 1(2), pp. 93-121.

MORENO, Raquel. (2012). "Sexismo y racismo en la gestión neoliberal de las migraciones: subtextos del contrato social". Oxímora Revista Internacional de Ética y Política, 1, pp.

CONTRERAS, Paola. (2016). "Migración hacia la Unión Europea y España. Debates, análisis y reflexiones en clave de los derechos humanos". Revista de Estudios Cotidianos, 4(1), pp. 61-91.

CONTRERAS, Paola. (2015). "Experiencias locales, situaciones globales. Inmigración femenina en el contexto Iberoamericano". Iberoamérica Social, 4, 142-152.

CONTRERAS, Paola; GÓMEZ, Ana y SANTA CRUZ, Úrsula. (2018). Mujeres migrantes como sujetos políticos Creando estrategias frente a las violencias. Consultado el 15 de febrero de 2019 en https://www.alianzaporlasolidaridad.org/wpcontent/uploads/ALIANZA-MUJERES-MIGRANTES-COMO-SUJETOS-ESTUDIO.pdf

Cruz Roja España. (2014). Informe de vulnerabilidad social 2013. Consultado el 4 de marzo de 2019 en 
http://www.sobrevulnerables.es/sobrevulnerables/ficheros/informes/informe_507/IVS 2013.pdf

DAVIS, Angela. (2004). Mujeres, raza y clase. Madrid: Akal.

DE LA SERNA, Cristina. (2014). "Uso de perfiles étnicos por parte de la policía en España: una oportunidad histórica de erradicarlos". Consultado el 20 de febrero de 2019 en

http://www.rightsinternationalspain.org/uploads/publicacion/c4f6a850303af9e65d91 572e29c6ddc457953f09.pdf

DELGADO, Manuel. (2009). "Seres de otro mundo: Sobre la función simbólica del inmigrante. En la dinámica del contacto: Movilidad, encuentro y conflicto en las relaciones interculturales". CIDOB. Colección monográfica, pp. 13-22.

DUSSEL, Enrique. (2000). "Europa, modernidad y eurocentrismo", en Lander, Edgardo (ed.) La colonialidad del saber: eurocentrismo y ciencias sociales. Buenos Aires: CLACSO.

FANON, Frantz. (2010). Piel negra, máscaras blancas. Madrid: Akal.

FERNÁNDEZ, Cristina. (2010). “Movilidad bajo sospecha. El conveniente vínculo entre inmigración y criminalidad en las políticas migratorias de la Unión Europea". Rev. Inter. Mob. Hum. 35, pp. 137-154.

GHOSH, Bimal. (2008). "Derechos humanos y migración: el eslabón perdido". Migración y desarrollo, 10, 37-63.

GUTIERREZ, Encarnación. (2010). "Valor afectivo, Colonialidad, feminización y migración". Consultado el 15 de febrero de 2019 en Http://eipcp.net/transversal/0112/gutierrez-rodriguez/es

GROSFOGUEL, Ramón. (2012). "El concepto de "racismo" en Michel Foucault y Frantz Fanon: ¿teorizar desde la zona del ser o desde la zona del no-ser?". Tabula Rasa, 16, pp. 79-102.

JARRÍN, Ariana. (2015). "Expulsados de España: el retorno forzoso de migrantes ecuatorianos en situación irregular". Iberoamérica Social: revista de estudios sociales, IV, pp.43-54

LUGONES, María. (2008). "Colonialidad y género". Tabula Rasa, 9, pp. 73-101.

MARTíNEZ, Javier y TÉLLEZ, Anastasia. (2017). “Desempleo, crisis económica y percepción sobre la población inmigrante en el Levante español". Universitas, XV(26), pp. 61-86.

MARTÍNEZ GARCÍA, Francisco; GARCÍA RAMÍREZ, Manuel; MAYA JARIEGO, Isidro. (1999). "El papel de los recursos sociales naturales en el proceso migratorio". Intervención psicosocial, 8 (2), 221-232.

MBEMBE, Achille. (2016). Crítica de la razón negra. Ensayo sobre el racismo contemporáneo. Barcelona: NED.

NASH, Jennifer. (2008). "Re-thinking intersectionality". Feminist Review, 89(1), 1-15 
Organización Internacional de las Migraciones, OIM. (2015). Análisis sobre la Situación Laboral de la Mujer Inmigrante en España. Análisis y proposiciones para la igualdad de trato y la lucha contra la discriminación. Consultado el 15 de febrero de 2019 en

https://www.comillas.edu/images/OBIMID/Estudio_Sobre_la_Situaci\%C3\%B3n_Labo ral_de_la_Mujer_Inmigrante._OIM_2015_1.pdf

ONRUBIA, Jorge. (2010). “Vivienda e Inmigración en España: situaciones y políticas públicas". Presupuesto y Gasto Público, 61, pp. 273-310-

GUZMÁN, Raquel. (2011). "De la perspectiva del género al paradigma interseccional". Aportes para el análisis de las migraciones feminizadas. En Isabel Vázquez (coord.). Libro de Actas: Investigación y género: III Congreso Universitario Nacional investigación y género. Universidad de Sevilla.

OSO, Laura y PARELLA, Sonia. (2012). "Presentación". En Cuadernos de relaciones laborales, 30(1), pp. 11-44.

OSO, Laura. (2003). Estrategias migratorias de las mujeres ecuatorianas y colombianas en situación irregular: servicio doméstico y prostitución en Galicia y Pamplona. Coruña: Universidade da Coruña, Facultade de Socioloxia.

PARELLA, Sonia. (2012). "Familia transnacional y redefinición de los roles de género: El caso de la migración boliviana en España". Papers. Revista de Sociología, 97(3), 661-684

PARELLA, Sonia; PETROFF, Alisa (2014). "Migración de retorno en España: Salidas de inmigrantes y programas de retorno en un contexto de crisis". CIDOB Anuario de la inmigración en España, pp. 63-87.

PEDONE, Claudia. (2007). "Familias transnacionales ecuatorianas: estrategias productivas y reproductivas". En Bretón, Víctor et al. (eds.). Ecuador y España frente al espejo o las múltiples caras de la ciudadanía. Madrid: Catarata.

PHOENIX, Ann; PATTYNAMA, Pamela. (2006). "Intersectionality". European Journal of Women's Studies, 13(3), 87-192.

QUIJANO, Aníbal. (2000). "Colonialidad del poder, eurocentrismo y América Latina", en Lander, Edgar (ed.). La Colonialidad del saber: eurocentrismo y ciencias sociales. Buenos Aires: Ed. Faces/UCV.

SÁNCHEZ, Alejandra. (2013). "Inmigración y Derechos Humanos en la UE. Análisis de la directiva 2008/115/CE". Revista Persona y derecho, 68, pp. 159-179.

SERVICIO PÚBLICO DE EMPLEO ESTATAL. (2016). Informe del Mercado de Trabajo de los Extranjeros Estatal. Consultado el 03 de marzo de 2019 en http://www.sepe.es/contenidos/que_es_el_sepe/publicaciones/pdf/pdf_mercado_trab ajo/imt2016_datos2015_estatal_extranjeros.pdf

SILVER, Hilary. (1994). "Social exclusion and social solidarity: three paradigms". International Labour Review, 13, pp. 533-378.

SINKE, Suzanne. (2006). "Gender and migration: Historical perspective". International Migration Review, 40, 82-103 
SOLANA, José. (2001). "Inmigración, hostilidades racistas y propuestas de hospitalidad". Gazeta de Antropología, 17. Consultado el 03 de marzo de 2019 en http://hdl.handle.net/10481/7467

SOS Racismo. (2015). Testing sobre discriminación a la población inmigrante en el acceso a la vivienda de alquiler. Consultado el 03 de marzo de 2019 en https://sosracismo.eu/wp-content/uploads/2016/07/Puertas-que-se-cierran-Testing.pdf

VAUGHAN-WILLIAMS, Nick. (2009). Border Politics: The Limits of Sovereign Power. Edinburgh: University Press.

VÁZQUEZ, María; VARGAS, Ingrid y ALLER, Beatriz. (2014). "Reflexiones sobre el impacto de la crisis en la salud y la atención sanitaria de la población inmigrante. Informe SESPAS 2014". Gaceta Sanitaria, 28(1), pp. 142-146.

\section{Leyes y decretos citados}

Comisión europea. (2015) Una agenda europea de migración. Consultado el 05 de diciembre de 2018 en

http://eur-lex.europa.eu/legal-content/EN/TXT/?uri=CELEX:52015DC0240

Ley Orgánica 4/2000. Consultado el 05 de diciembre de 2018 en

https://www.boe.es/buscar/act.php?id=BOE-A-2000-544

Ley Orgánica 4/2015. Consultado el 05 de diciembre de 2018 en

https://boe.es/buscar/doc.php?id=BOE-A-2015-3442

Real Decreto-ley 16/2012. Consultado el 05 de diciembre de 2018 en

https://www.boe.es/buscar/act.php?id=BOE-A-2012-5403

Real Decreto 162/2014. Consultado el 05 de diciembre de 2018 en

https://www.boe.es/buscar/doc.php?id=BOE-A-2014-2749

Reglamento 2016/1624/UE del Parlamento y del Consejo, sobre la Guardia Europea de Fronteras y Costas. Consultado el 05 de diciembre de 2018 en

https://www.boe.es/doue/2016/251/L00001-00076.pdf

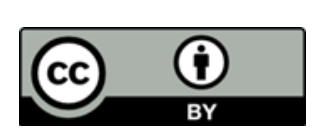

